\title{
Comparison of Viral Hepatitis-Associated Hepatocellular Carcinoma Due to HBV and HCV - Cohort from Liver Clinics in Pakistan
}

\author{
Alvina Munaf ${ }^{1}$, Muhammad Sadik Memon'*, Prem Kumar ${ }^{1}$, Sultan Ahmed ${ }^{2}$, \\ Maheshwari Bhunesh Kumar ${ }^{3}$
}

\begin{abstract}
Background: Hepatocellular carcinoma (HCC) is the first cause of death in cirrhotic patients, mostly due to viral hepatitis with $\mathrm{HCV}$ or $\mathrm{HBV}$ infection. This study was performed to estimate the true prevalence of viral hepatitis-related HCC and the demographic and clinical-pathological associations with the two virus types. Materials and Methods: This cross sectional observational study enrolled clinical data base of 188 HCC patients and variables included from baseline were age, sex, area of residence, clinical-pathological features such as underlying co-morbidity, presence or absence of liver cirrhosis, macrovascular involvement, tumor extension and metastasis, liver lobes involved, serum alpha-fetoprotein level, and hepatitis serologies. Results: Overall prevalence of $\mathrm{HCV}$ - and HBV-related HCC was $66.0 \%$ and $34.0 \%$, respectively. Patients with HCV were more likely to develop HCC at advanced age $(52.4 \pm 11.9$ vs. $40.7 \pm 12.09$ years $)$, with highly raised serum AFP levels ( $\geq 400 \mathrm{ng} / \mathrm{ml}) 78.2 \%$ (HBV 67.1\%), large tumor size (HCV-66\% $>5 \mathrm{~cm}, \mathrm{HBV}-59.3 \%$ ), and presence of portal vein thrombosis $(8.06 \%, \mathrm{HBV} 1.56 \%)$. A binominal multivariate analysis showed that HCV-HCC group were more likely to be cirrhotic $(\mathrm{OR}=0.245,95 \% \mathrm{CI}: 0.117,0.516)$ and had more than two times higher rate of solitary macrovascular involvement $(\mathrm{OR}=2.533,95 \% \mathrm{CI}$ : $1.162,5.521)$ as compared with HBV associated HCC. Conclusions: Statistically significant variations were observed from baseline to clinical-pathological characteristics in HCV vs HBV associated HCC. Our study suggests prompt and early screening for high risk patients so that the rate of progression of these chronic viral diseases to cirrhosis and cancer can be decreased.
\end{abstract}

Keywords: Hepatocellular carcinoma - viral hepatitis - HCV - HBV - tumour characteristics

Asian Pac J Cancer Prev, 15 (18), 7563-7567

\section{Introduction}

Hepatocellular carcinoma (HCC) is one of the most common primary malignancies of the liver which is not only increasing the global incidence but also is a major cause of cancer related mortality particularly with a male predominance (Hiotis et al., 2012; Etsuji, 2013) even after advances in the treatment strategies (Okonkwo et al., 2011). Recent literature suggest a rise in the incidence of HCC $\sim 500,000$ and mortality rate of $>600,000$ per year (Hamid et al., 2013). Globally, HCC took the third place in cancer related mortality and is also thought to be the first cause of death in cirrhotic patients (Parkin et al., 2001). The epidemiological distribution of HCC varies from one area to another area, the Southeast Asia and sub-Saharan Africa contributes mainly (Parikh and Hyman, 2007; Naqi et al., 2014) and lower, but on the increase, in North America and most of Europe (Venook et al., 2010). In Pakistan prevalence of HCC varies from
$3.7 \%$ of all malignant tumors to $16 \%$ (Butt et al., 2012).

Irrespective of country origin, a great proportion of $\mathrm{HCC}$ is caused by viral infections, the major contributors are hepatitis B virus (HBV) and hepatitis C virus (HCV) (Blonski et al., 2010; Ayub et al., 2013; Ali et al., 2014), as compare to other less common risk factors of HCC such as aflatoxin (Lv et al., 2014), cirrhosis due to alcohol (Cheng et al., 2013; Kikuchi et al., 2014), fatty liver disease , obesity, smoking, diabetes, and iron overload (Blonski et al., 2010; Ayub et al., 2013; Ali et al., 2014). Bosan et al. (2010). has conducted systematic review on viral hepatitis in which authors included 220 related abstracts and showed prevalence of $\mathrm{HBs} \mathrm{Ag}$ and anti-HCV was $2.6 \%$ and $5.3 \%$ in a general population, respectively. Overall prevalence of HCC due to underlying viral infection was $87.4 \%$ and among them causative viral infection of cirrhosis was mainly HCV (67.9\%) and then HBV (21.8\%) in Pakistan (Butt et al., 2013) but this study did not compare the data of HCV and HBV related HCC

${ }^{1}$ Asian Institute of Medical Sciences, ${ }^{3}$ Department of Medicine, Liaquat University of Medical \& Health Sciences, Hyderabad, ${ }^{2}$ Department of Gastroenterology \& Hepatology, Chandka Medical College \& Hospital, Larkana, Pakistan *For correspondence: drsadikmemon@hotmail.com 
and also mainly encompasses prognostic factors of viral marker negative hepatocellular carcinoma in Pakistan.

Previous epidemiological literatures decline their statistical conclusions and suggest both viral infections are more common in developing countries than developed countries with predominance of $\mathrm{HCV}$ infection. Available data focused on the HCV-HCC group or HBV-HCC group, but to our best knowledge till now no study has been conducted from South-east Asia that shows combined prevalence of HCV-HCC and HBV-HCC along with combined clinical and pathological association of these viruses with HCC. Therefore, this study was indicated for estimating the true prevalence of $\mathrm{HCV}$ and HBV related HCC and also we explored the demographic and clinicalpathological association among them.

\section{Materials and Methods}

\section{Study population and duration}

This cross sectional study enrolled clinical data base of HCC diagnosed patients who attended the Isra University Hospital (IUH), Section of Gastroenterology and Hepatology and Asian Institute of Medical Sciences (AIMS) hospital, Hyderabad, Pakistan between 2009 and 2013. IUH is a 300 -bedded while AIMS is a 150-bedded private, tertiary care teaching hospital that specially serves the residents of Hyderabad (population 2 million) and the surrounding 6-8 districts of Sindh province. The study protocol was assessed and approved by two involved institutes and the study was conducted in compliance with the Helsinki Declaration.

Potential participants after taking informed consent for participation in the study were recruited. Data of basic demographic characteristics were collected such as age, sex, education level, and area of residence. Structured questionnaire was designed to record the data regarding clinical and pathological features of $\mathrm{HCC}$, including: Underlying cause of HCC, child-Pugh class, Alphafetoprotein level, size and stage of the tumor, presence or absence of distant metastasis, lobes of the liver involved, stage of macro-vascular involvement, and presence or absence of portal vein thrombosis. Other than HCC, data were also collected to record patient's co-morbidity such as hypertension, diabetes mellitus, and underlying liver cirrhosis.

\section{Laboratory parameters}

Senior laboratory technologist drew $5 \mathrm{ml}$ venous blood sample using a sterilized disposable syringe, and then the sample was used for the detection of hepatitis $C$ virus and hepatitis $B$ virus infection by enzyme linked immunosorbent assay (ELISA). Other laboratory investigations such as liver function tests i.e. total bilirubin, serum Alanine aminotransferase (ALT), serum Aspartate aminotransferase (AST), alpha fetoprotein levels, serum albumin, and serum creatinine levels were also performed.

\section{Diagnosis of HCC and cirrhosis}

HCC was confirmed if the patient had previous recent reliable reports available. Alternatively, patients in the absence of reports, HCC was diagnosed if the patients presented with clinical features suggestive of HCC and then diagnosis was confirmed by typical features of HCC on triple-phase computed tomography (CT) scan with intravenous contrast or magnetic resonance imaging (MRI) tests showing hypervascular solid liver mass along with evidence of elevated serum alpha-fetoprotein levels with or without histological verification (Hussain and El-Serag, 2009). Liver cirrhosis was confirmed if the patient had previous recent reliable reports available or by using clinical and laboratory features suggestive of portal hypertension i.e. esophageal varices diagnosed by using upper gastrointestinal endoscopy procedure, suggestive radiological investigations (Shaheen and Myers, 2007; Bruix and Sherman, 2011), and liver biopsy where needed. Liver severity was assessed using the Child-Pugh classification system (Pugh et al., 1973).

\section{Clinical staging of $\mathrm{HCC}$}

The Macrovascular involvement was divided into two groups (i) Solitary and (ii) multiple. Extension of tumor was classified into three categories as, (i) $<5 \mathrm{~cm}$, (ii) $5-10 \mathrm{~cm}$, and (iii) $\geq 10 \mathrm{~cm}$. Furthermore, information was also recorded for Presence or absence of tumor metastasis, liver lobes involvement (right, left, or both liver lobes involved), and whether underlying portal vein thrombosis is present or not.

\section{Statistical analysis}

We used Statistical Package for Social Sciences, version 16 (SPSS Inc, Chicago, IL, USA) for data entry and to analyze the collected data. Categorical data such as sex, education level, area of residence, and co-morbidity were presented as frequency and percentage. The frequency of HCV and HBV seropositives among HCC cohorts was calculated and also presented as frequency and percentage and we used chi square and fisher's exact test for comparison between them. Quantitative data such as age and laboratory investigations among HCV and HBV associated HCC were compared by using student t-test. Multiple logistic regression model was introduced with the dependent variables such as gender, area of residence, education status, co-morbidity, clinical-pathological features, and liver cirrhosis. Initially, in order to include important variables, factors having significance $p<0.25$ in univariate analysis were included in the multivariate analysis. The final model was selected using a forward method and $p \leq 0.05$.

\section{Results}

Baseline characteristics of study population shown in Table 1 at enrolment, including gender, Education status, co-morbidity, underlying presence or absence of cirrhosis, Child-Pugh class of patients infected with viral hepatitis, and alpha-fetoprotein levels. Male proportion observed to be predominant in both $\mathrm{HCV}(62 \%)$ and $\mathrm{HBV}(75.4 \%)$ infected $\mathrm{HCC}$ population. Overall prevalence of $\mathrm{HCV}$ and HBV in patients having HCC was $65.95 \%$ and $34.04 \%$, respectively. Presence of underlying liver cirrhosis was more significantly associated with HCV seropositives as 
compared to HBV seropositive patients $(p<0.05)$. Rest of the baseline characteristics were insignificantly associated with $\mathrm{HCC}$ among $\mathrm{HCV}$ and $\mathrm{HBV}$ patients $(p>0.05)$.

Table 2 shows comparison of means between $\mathrm{HCV}$ and HBV seropositive patients with HCC. In univariate analysis, mean age difference (11.6 years), and total bilirubin levels $(-1.91 \mathrm{mg} / \mathrm{dl})$ were the only statistically significant observations noted among HCV-HCC group $(p<0.05)$ as compared with HBV-HCC group (Table 2).

Macrovascular involvement, tumor extension, metastasized tumor, more than one lobe involvement, and presence of portal vein thrombosis are major risk factors associated with poor prognosis among HCC patients at the time of initial diagnosis. Our study shows, patients with $\mathrm{HCV}$ seropositives were more likely $(p=0.016)$ to have Macrovascular involvement as compared with HBV seropositives. Rest of the selected factors did not show any significant association.

A binominal multivariate analysis showed that patients

Table 1. Clinical Characteristics of HCC in HCV and HBV Patients

\begin{tabular}{llrrrc}
\hline Category & & $\begin{array}{c}\text { All } \\
(\mathrm{n}=188)\end{array}$ & $\begin{array}{c}\mathrm{HCV} \\
(\mathrm{n}=124)\end{array}$ & $\begin{array}{c}\mathrm{HCV} \\
(\mathrm{n}=64)\end{array}$ & P \\
& & No. $(\%)$ & No. $(\%)$ & No. $(\%)$ & \\
\hline Gender & Male & $123(65.4)$ & $77(62.0)$ & $46(75.4)$ & 0.182 \\
& Female & $65(34.5)$ & $47(37.9)$ & $18(28.1)$ & \\
Residence & Rural & $99(52.6)$ & $61(49.1)$ & $38(59.3)$ & 0.185 \\
& Urban & $89(47.3)$ & $63(50.8)$ & $26(40.6)$ & \\
Education status (years $)$ & & & & \\
& $<5$ & $95(50.5)$ & $66(53.2)$ & $58(90.6)$ & 0.304 \\
& $\geq 5$ & $93(49.4)$ & $29(23.3)$ & $26(40.6)$ & \\
Co-Morbidity & Hypertension & $54(28.7)$ & $38(30.6)$ & $16(25)$ & 0.418 \\
& Diabetes & $58(30.8)$ & $41(33.0)$ & $17(26.5)$ & 0.36 \\
Cirrhosis & No & $150(79.7)$ & $109(87.9)$ & $41(64.0)$ & $<0.001 *$ \\
& Yes & $38(20.2)$ & $15(12.0)$ & $23(35.9)$ & \\
Child Class & A & $107(56.9)$ & $72(58)$ & $35(54.6)$ & 0.896 \\
& B & $55(29.2)$ & $35(28.2)$ & $20(31.2)$ & \\
& C & $26(13.8)$ & $17(13.7)$ & $9(14.0)$ & \\
AFP Levels & 0-20 & $20(10.6)$ & $10(8.0)$ & $10(15.6)$ & 0.192 \\
(ng/ml) & $\geq 21-399$ & $28(14.8)$ & $17(13.7)$ & $11(17.1)$ & \\
& $\geq 400$ & $140(74.4)$ & $97(78.2)$ & $43(67.1)$ & \\
\hline *AFP: Alfa-fetoprotein* *Statistically significant p values <0.05 & &
\end{tabular}

with $\mathrm{HCC}$ due to $\mathrm{HCV}$ infection were more likely to be cirrhotic (OR=0.24, 95\%CI: $0.11,0.51)$ and had more than two times higher rate of solitary Macrovascular involvement ( $\mathrm{OR}=2.53,95 \% \mathrm{CI}: 1.16,5.52)$ as compared with HBV associated HCC $(p<0.05)$ (Table 4).

\section{Discussion}

Hepatocellular carcinoma is mainly caused by Hepatitis C and Hepatitis B viruses, but latter showed predominance, comparatively worldwide and correlated $\mathrm{HBV}$ directly as a cause of $\mathrm{HCC}$ rather than HCV whose relation with HCC is still unclear (Shepard et al., 2006; Di Bisceglie, 2009). Because of the geographical differences and risk factors, the epidemiological burden of $\mathrm{HCV}$ and $\mathrm{HBV}$ has been observed different in different areas of the world. In developing countries due to high burden of $\mathrm{HCV}$ infection as compared to HBV such as in Taiwan (HCV $17.0 \%$, HBV 13.8\%) (Kao et al., 2011), Guam (HCV $19.6 \%$, HBV 18\%) (Haddock et al., 2013), and Pakistan (HCV 4.8\%,HBV 2.5\%) (Rehman et al., 1996; Raza et al., 2007; Qureshi et al., 2010; Butt et al., 2012; ) will possibly

\section{Table 3. Clinical Stage of Patients with HCC}

\begin{tabular}{|c|c|c|c|c|c|}
\hline & & $\begin{array}{c}\text { All } \\
(\mathrm{n}=188)\end{array}$ & $\begin{array}{c}\text { HCV } \\
(n=124)\end{array}$ & $\begin{array}{l}\text { HBV } \\
(n=64)\end{array}$ & $P$ value \\
\hline \multicolumn{6}{|c|}{ Macrovascular involvement } \\
\hline & Solitary & $153(81.3)$ & $107(86.2)$ & $46(71.8)$ & \multirow[t]{2}{*}{$0.016^{*}$} \\
\hline & Multiple & $35(18.6)$ & $17(12.7)$ & $18(28.1)$ & \\
\hline \multicolumn{6}{|c|}{ Tumor Extension - cm } \\
\hline & $<5$ & $68(36.17)$ & $42(33.8)$ & $26(40.6)$ & \multirow{3}{*}{0.258} \\
\hline & $5-10$ & $83(44.1)$ & $60(48.3)$ & $23(35.9)$ & \\
\hline & $\geq 10$ & $37(19.6)$ & $22(17.70$ & $15(23.4)$ & \\
\hline \multicolumn{6}{|c|}{ Tumor Metastasis } \\
\hline & Present & $72(38.2)$ & $49(39.5)$ & $23(35.9)$ & \multirow[t]{2}{*}{0.632} \\
\hline & Absent & $116(61.7)$ & $75(60.4)$ & $41(64.0)$ & \\
\hline \multicolumn{6}{|c|}{ Liver lobe involved } \\
\hline & Right & $119(63.2)$ & $83(66.9)$ & $36(56.2)$ & \multirow{3}{*}{0.358} \\
\hline & Left & $54(28.7)$ & $32(24.8)$ & $22(34.3)$ & \\
\hline & Both & $15(9.57)$ & $9(7.25)$ & $6 \quad(9.37)$ & \\
\hline \multirow[t]{2}{*}{ PVT } & Present & $11(5.85)$ & $10(8.06)$ & $1 \quad(1.56)$ & \multirow{2}{*}{0.072} \\
\hline & Absent & $177(62.2)$ & $114(91.9)$ & $63(98.40)$ & \\
\hline
\end{tabular}

Table 2. Unpaired T-Test for the Mean Differences between HCV and HBV - HCC Positive Patients

\begin{tabular}{|c|c|c|c|c|c|}
\hline \multirow[t]{4}{*}{ Parameters } & \multicolumn{2}{|c|}{ HCC cases } & \multirow{4}{*}{$\begin{array}{c}\text { Mean difference } \\
\mathrm{HCV} / \mathrm{HBV}\end{array}$} & \multirow{4}{*}{ P Value } & \multirow{4}{*}{$95 \% \mathrm{CI}$} \\
\hline & $\mathrm{HCV}$ & HBV & & & \\
\hline & $\mathrm{N}=114$ & $\mathrm{~N}=64$ & & & \\
\hline & Mean \pm SD & Mean \pm SD & & & \\
\hline Age-years & $52.35 \pm 11.9$ & $40.67 \pm 12.09$ & 11.683 & $<0.001 *$ & $8.049,15.317$ \\
\hline T. Bilirubin - mg/dl & $2.08 \pm 2.72$ & $4.00 \pm 6.92$ & -1.916 & $0.007^{*}$ & $-3.313,-0.520$ \\
\hline Albumin - mg/dl & $3.22 \pm 1.37$ & $3.24 \pm 2.27$ & -0.018 & 0.944 & $-0.546,0.508$ \\
\hline Creatinine - mg/dl & $1.77 \pm 1.89$ & $2.10 \pm 1.86$ & -0.325 & 0.263 & $-0.898,0.247$ \\
\hline ALT & $75 \pm 45.1$ & $69.5 \pm 60.0$ & 5.505 & 0.481 & $-9.880,20.889$ \\
\hline $\mathrm{AST}$ & $103 \pm 79.0$ & $81.3 \pm 55.0$ & 21.64 & 0.052 & $-0.151,43.441$ \\
\hline
\end{tabular}

Table 4. Comparative Multivariate Analysis between HBV and HCV - HCC Patients

\begin{tabular}{|c|c|c|c|c|c|c|c|}
\hline & & $\begin{array}{c}\text { All } \\
(\mathrm{n}=188) \\
\text { No. }(\%)\end{array}$ & $\begin{array}{c}\text { HCV } \\
(\mathrm{n}=124) \\
\text { No. }(\%)\end{array}$ & $\begin{array}{c}\text { HBV } \\
(\mathrm{n}=64) \\
\text { No. }(\%)\end{array}$ & Adjusted OR & $95 \% \mathrm{CI}$ & $\mathrm{p}$ value \\
\hline \multirow[t]{2}{*}{ Cirrhosis } & No & $38(20.2)$ & $15(12.0)$ & $23(35.9)$ & 1 & $0.117,0.516$ & $<0.001 *$ \\
\hline & Yes & $150(79.7)$ & $109(87.9)$ & $41(64.0)$ & 0.245 & & \\
\hline \multirow[t]{2}{*}{ Macrovascular involvement } & Solitary & $153(81.3)$ & $107(86.2)$ & $46(71.8)$ & 1 & $1.162,5.521$ & $0.019 *$ \\
\hline & Multiple & 35 (18.6) & $17(12.7)$ & $18(28.1)$ & 2.533 & & \\
\hline
\end{tabular}


leads to an increase in both the incidence and prevalence of $\mathrm{HCV}$ related HCC. In our study, the prevalence of $\mathrm{HCV}$ as a risk factor for HCC is around double (66\%) when comparing it with HBV associated HCC (34\%). This significant statistics potentially demonstrate the disparity in risk factors at initial cancer diagnosis. All other previous studies are confirming $\mathrm{HBV}$ as a major risk factor for causing HCC (Brechot et al., 2010; Chan et al., 2004; Fan et al., 2013; Yohwan et al., 2013), but these studies were mainly conducted on a population from developed countries.

In our study, proportion of $\mathrm{HCV}$ associated $\mathrm{HCC}$ were older in age when comparing it with HBV associated HCC patients with a mean age difference of more than 10 years. The finding from our study is consistent with previous studies, included data from United States of America (Hiotis et al., 2012) and Japan (Tanizaki et al., 1997). One of the sequential reasons behind this difference can be explained by recalling the duration of progression these two diseases takes to develop chronic severe infections, cirrhosis, and hepatocellular carcinoma. Among $80 \%$ of HCV individuals, 20\% will develop cirrhosis or HCC and these patients usually diagnosed in the second or third decade after infection (Michielsen et al., 2005).

In a recent paper, at the time of initial diagnosis of $\mathrm{HCC}$, irrespective of viral etiology, Child-Pugh class A was observed in more than $50 \%$ of the patients. When comparing the Child-Pugh class with respect to viral etiology, Child-Pugh class A, B, and C were equally distributed in both $\mathrm{HCV}$ and HBV related HCC patients in our study. A great proportion of HCC population which consisted of child class A and child class B was the indicator of early stage diagnosis that we have also observed in our study. The mechanical sequence can also be verified from previously published data that shows agreement with our study (El-Serag, 2011).

Alpha-fetoprotein, normal value ranges from 10 $20 \mathrm{ng} / \mathrm{ml}$ is considered to be the strong screening and confirmatory tumor marker for HCC if levels are more than 200 or 400ng/ml (Sarwar et al, 2003). Patients infected with viral hepatitis $\mathrm{C}$ and $\mathrm{B}$ are at very high risk of $\mathrm{HCC}$ development in the presence of cirrhosis and rising AFP levels (Davis et al., 2008). Same findings were observed in our study, one third of study proportion had an AFP levels greater than $400 \mathrm{ng} / \mathrm{ml}$ and this high titer was seen in both $\mathrm{HCV}$ and $\mathrm{HBV}$ associated $\mathrm{HCC}$ with insignificant difference.

One of the additional significant clinical-pathologic differences in patients with HCC was also observed according to underlying viral hepatitis status; mean difference in the total bilirubin level was significantly higher observed in HBV-HCC group than HCV-HCC group. However, previous literature reveals an abnormal liver function tests including total bilirubin in HCC patients (Lopez et al., 1996). On the other hand, data is limited regarding differences in the liver function tests in patients with HCV or HBV associated HCC.

Oncologic variables with established prognostic significance were evaluated according to viral hepatitis status. Our study also observed that odds of being solitary Macrovascular involvement among HCV-infected HCC patients were 2.5 times higher than HBV-infected HCC patients, which was the only oncologic variable that achieved statistical significance. Rest of the oncologic variables did not achieve statistical significance but occurred with high frequency in HCV associated HCC. Importantly, studies published in other areas describe disparate trends, in which prognostic oncologic variables were occurred with high frequency in HBV-HCC group (Hiotis et al., 2012). This relationship proves geographical and time-dependent variation and its relationship with difference in the frequency of prognostic oncologic variables, that developing countries due to high prevalence of HCV-HCC, prognostic oncologic variables were also high as compared from the data available from developed countries (Lavanchy, 2004; Khan et al., 2009; Butt et al., 2012; Butt et al., 2013; Abbas, 2013).

In conclusion, in summary, burden of HCV-HCC group is far more common than HBV-HCC and among them majority comprises of males. HCV associated HCC group were more likely to present with advanced age, presence of liver cirrhosis, and with $>400 \mathrm{ng} / \mathrm{ml}$ raised AFPlevels. Underlying co-morbidity such as hypertension and diabetes mellitus does not contribute any significant association in both virus associated HCC groups. Data from our study filled the scientific gap of HCV and HBV related HCC along with their relationship from baseline to clinical-pathological features in the region of Southeast Asia. Our study suggests prompt and early screening for HCC in high risk patients, particular emphasis should be given on HCV patients from developing countries so that the rate of progression of these chronic diseases to cirrhosis and cancer can be decreased.

\section{References}

Abbas Z (2013). Hepatocellular carcinoma in Pakistan. J Coll Physicians SurgPak, 23, 769-770.

Ali S, Ahmad A, Khan RS et al (2014). Genotyping of HCV RNA reveals that $3 \mathrm{a}$ is the most prevalent genotype in mardan, pakistan. Adv Virol, 2014, 606201.

Ayub A, Ashfaq UA, Haque A (2013). HBV induced HCC: major risk factors from genetic to molecular level. Biomed Res Int, 2013, 810461.

Blonski W, Kotlyar DS, Forde KA (2010). Non-viral causes of hepatocellular carcinoma. World J Gastroenterol, 16, 3603-15.

Bosan A, Qureshi H, Bile KM, et al (2010). A review of hepatitis viral infections in Pakistan. Pak Med Assoc, 60, 1045-58.

Brechot C, Kremsdorf D, Soussan P, et al (2010). Hepatitis $\mathrm{B}$ virus (HBV)-related hepatocellular carcinoma (HCC): molecular mechanisms and novel paradigms. Pathol Biol, 58, 278-87.

Bruix J, Sherman, M (2011). Management of hepatocellular carcinoma: an update. Hepatology, 53, 1020-2.

Butt AS, Abbas Z, Jafri W (2012). Hepatocellular carcinoma in pakistan: where do we stand? Hepat Mon, 12, 6023.

Butt AS, Hamid S, Wadalawala AA, et al (2013). Hepatocellular carcinoma in Native South Asian Pakistani population; trends, clinico-pathological characteristics \& differences in viral marker negative \& viral-hepatocellular carcinoma. BMC Res Notes, $6,137$.

Chan HL, Hui AY, Wong ML, et al (2004). Genotype Chepatitis $\mathrm{B}$ virus infection is associated with an increased risk of hepatocellular carcinoma. Gut, 53, 1494-8. 
Davis GL, Dempster J, Meler JD, et al (2008). Hepatocellular carcinoma: management of an increasingly common problem. Proc Bayl Univ Med Cent, 21, 266-80.

Di Bisceglie AM (2009). Hepatitis B and hepatocellular carcinoma. Hepatology, 49, 56-60.

El-Serag HB (2011). Hepatocellular carcinoma. N Engl J Med, 365, 1118-27.

Fan JH, Wang JB, Jiang Y, et al (2013). Attributable causes of liver cancer mortality and incidence in China. Asian Pac J Cancer Prev, 14, 7251-6.

Haddock R, Paulino Y, Bordallo R (2013). Viral hepatitis and liver cancer on the island of guam. Asian Pac J Cancer Prev, 14, 3175-6.

Hamid AS, Tesfamariam IG, Zhang Y, Zhang ZG (2013). Aflatoxin B1-induced hepatocellular carcinoma in developing countries: Geographical distribution, mechanism of action and prevention. Oncol Lett, 5, 1087-92.

Hiotis SP, Rahbari NN, Villanueva GA, et al (2012). Hepatitis $B$ vs. hepatitis $C$ infection on viral hepatitis-associated hepatocellular carcinoma. BMC Gastroenterol, 12, 64 .

Hussain K, El-Serag HB (2009). Epidemiology, screening, diagnosis and treatment of hepatocellular carcinoma. Minerva Gastroenterol Dietol, 55, 123-38.

Kao WY, Su CW, Chau GY, et al (2011). A comparison of prognosis between patients with hepatitis $\mathrm{B}$ and $\mathrm{C}$ virusrelated hepatocellular carcinoma undergoing resection surgery. World J Surg, 35, 858-67.

Khan A, Tanaka Y, Azam Z, et al (2009). Epidemic spread of hepatitis $\mathrm{C}$ virus genotype $3 \mathrm{a}$ and relation to high incidence of hepatocellular carcinoma in Pakistan. J Med Virol, 81, 1189-97.

Kikuchi L, Oliveira CP, Carrilho FJ (2014). Nonalcoholic fatty liver disease and hepatocellular carcinoma. Biomed Res Int, 2014, 106247.

Lavanchy D (2004). Hepatitis B virus epidemiology, disease burden, treatment, and current and emerging prevention and control measures. J Viral Hepat, 11, 97-107.

Lopez JB, Balasegaram M, Thambyrajah V, Timor J (1996). The value of liver function tests in hepatocellular carcinoma. Malays J Pathol, 18, 95-99.

Michielsen PP, Francque SM, Van Dongen JL (2005). Viral hepatitis and hepatocellular carcinoma. World J Surg Oncol, 3, 27.

Naqi N, Ahmad S, Murad S, Khattak J (2014). Efficacy and safety of sorafenib-gemcitabine combination therapy in advanced hepatocellular carcinoma: an open-label Phase II feasibility study. Hematol Oncol Stem Cell Ther, 7, 27-31.

Okamoto E (2013). Cohort analysis of incidence/mortality of liver cancer in Japan through logistic curve fitting. Asian Pac J Cancer Prev, 14, 5891-3

Okonkwo UC, Nwosu MN, Ukah C, Okpala OC, Ahaneku JI (2011). The clinical and pathological features of hepatocellular carcinoma in Nnewi, Nigeria. Niger J Med, 20, 366-71.

Parikh S, Hyman D (2007). Hepatocellular cancer: a guide for the internist. Am J Med, 120, 194-202.

Parkin DM, Bray F, Ferlay J, Pisani P (2001). Estimating the world cancer burden: Globocan 2000. Int J Cancer, 94, 153-6.

Pugh RN, Murray-Lyon IM, Dawson JL, Pietroni MC, Williams R (1973). Transection of the oesophagus for bleeding oesophageal varices. Br J Surg, 60, 646-9.

Qureshi H, Bile KM, Jooma R, Alam SE, Afridi HU (2010). Prevalence of hepatitis B and C viral infections in Pakistan: findings of a national survey appealing for effective prevention and control measures. East Mediterr Health $J$, 16, 15-23.

Raza SA, Clifford GM, Franceschi S (2007). Worldwide variation in the relative importance of hepatitis $B$ and hepatitis $\mathrm{C}$ viruses in hepatocellular carcinoma: a systematic review. Br J Cancer, 96, 1127-34.

Rehman K, Khan AA, Haider Z, et al (1996). Prevalence of seromarkers of $\mathrm{HBV}$ and $\mathrm{HCV}$ in health care personnel and apparently healthy blood donors. J Pak Med Assoc, 46, $152-4$

Ryder SD (2003). Guidelines for the diagnosis and treatment of hepatocellular carcinoma (HCC) in adults. Gut, 52, 1-8.

Sarwar S, Khan AA, Tarique S (2014). Validity of alpha fetoprotein for diagnosis of hepatocellular carcinoma in cirrhosis. J Coll Physicians Surg Pak, 24, 18-22.

Shaheen AA, Myers RP (2007). Diagnostic accuracy of the aspartate aminotransferase-to-platelet ratio index for the prediction of hepatitis C-related fibrosis: a systematic review. Hepatology, 46, 912-21.

Shepard CW, Simard EP, Finelli L, Fiore AE, Bell BP (2006). Hepatitis B virus infection: epidemiology and vaccination. Epidemiol Rev, 28, 112-25.

Su CH, Lin Y, Cai L (2013). Genetic factors, viral infection, other factors and liver cancer: an update on current progress. Asian Pac J Cancer Prev, 14, 4953-60.

Tanizaki H, Ryu M, Kinoshita T, et al (1997). Comparison of clinical features and survival in patients with hepatitis B and C virus-related hepatocellular carcinoma. Jpn J Clin Oncol, 27, 67-70.

Venook AP, Papandreou C, Furuse J, De Guevara LL (2010). The incidence and epidemiology of hepatocellular carcinoma: a global and regional perspective. Oncologist, 4, 5-13.

Yeo Y, Gwack J, Kang S, et al (2013). Viral hepatitis and liver cancer in Korea: an epidemiological perspective. Asian Pac J Cancer Prev, 14, 6227-31. 